\title{
HACIA UN ESTÁNDAR DE PRUEBA CIVIL
}

\author{
TOWARDS A CIVIL STANDARD OF PROOF
}

Jorge Larroucau Torres*

\begin{abstract}
RESUMEN: El estándar de prueba es el umbral que permite saber si un relato puede considerarse probado dentro de un proceso. La elección del estándar de prueba supone siempre una decisión normativa, por lo que nos exige saber cuáles son las cuestiones valiosas que se perderán a causa de una sentencia errónea. Aquí ensayo dos formas racionales de comprender al estándar probatorio: (i) un enfoque externo, basado en normas de peso probatorio, afín al modelo usado por la justicia chilena durante el siglo XX y (ii) un enfoque interno, anclado en la imparcialidad del juez y su convicción, además de una posible síntesis de ambos mediante la estrategia de la inferencia a la mejor explicación. Para este análisis uso de ejemplo el caso de la responsabilidad civil y sigo de cerca el debate angloamericano con el deseo de aportar a un desafío impostergable que tiene por delante nuestra administración de justicia.
\end{abstract}

Palabras claves: Estándar de prueba civil, reglas de peso probatorio, convicción judicial, inferencia a la mejor explicación

ABSTRACT: The standard of proof is the threshold that allows knowing if a story can be considered to be proved within a process. The election of the standard of proof always presumes a normative decision that demands to know the valuable things that will be lost because of a wrong sentence. Here I attempt two rational forms of understanding the evidentiary standard: (i) an external approach based on rules of evidential weight related to the pattern used by the Chilean justice during the XX century and (ii) an internal approach fixed on the judge's impartiality and its conviction, in addition of a possible synthesis of both through the strategy of inference to the best explanation. For this analysis I use the example of the case of civil liability and I follow the Anglo-American debate very closely with a desire to contribute to a challenge put off ahead for our administration of justice.

Key words: Civil Standard of Proof, Rules of Evidential Weight, Judicial Conviction, Inference to the Best Explanation

\section{LA DIFERENCIA ENTRE PROBAR Y NO PROBAR}

Cuando lo que se espera de un tribunal es que juzgue los hechos de un modo racional y controlable, la figura del estándar de prueba empieza a adquirir un fuerte protagonismo. Un estándar probatorio es la respuesta que ofrece la ley procesal ante la inquietud de cuándo una narración se encuentra acreditada (o descartada) al concluir el litigio. O sea, se trata de una norma (legal o no) que reparte los riesgos de errores -el peligro de que el juez

\footnotetext{
*Profesor de Derecho Civil, Universidad Alberto Hurtado. Correo electrónico: jlarrouc@uahurtado.cl. Licenciado en Ciencias Jurídicas y Sociales, Universidad de Concepción; Doctor en Derecho, Universidad de Chile.

Me han sido provechosas las notas de los dos árbitros de la Revista Chilena de Derecho a una versión previa de este trabajo, cuyas sugerencias agradezco.
} 
se equivoque en la sentencia definitiva- en escenarios cuyo rasgo común es la incertidumbre $^{1}$. En cualquiera de nuestros procesos judiciales se busca información sobre los hechos, pero ninguno de ellos consigue recopilar todos los datos. Este es un rasgo enfatizado primero por la literatura angloamericana, pero que hoy el debate continental también reconoce, por ejemplo, en la dogmática procesal española ${ }^{2}$ y chilena ${ }^{3}$. ¿Qué implica este déficit de información al valorar las pruebas? Que el juez siempre podrá sospechar que las cosas pudieron ocurrir de otro modo. Para aplacar estas dudas es que los tribunales acuden a un estándar probatorio como la pieza procesal que "refleja nuestra decisión colectiva de colocar el umbral en un punto y no en otro" ${ }^{4}$, según sean los bienes en juego. De allí, entonces, que apostar por un estándar en lugar de otro precisa de una deliberación normativa previa ${ }^{5}$.

La lectura tradicional de los juicios angloamericanos muestra con claridad este punto. Dentro del sistema angloamericano la justicia civil confía en un estándar de probabilidad prevaleciente, mientras que la litigación continental espera que el juez se encuentre convencido de la verdad de los hechos ${ }^{6}$. En el Common Law hay un relativo acuerdo en cuanto a que un estándar de probabilidad prevaleciente (o regla $\mathrm{P}>0,5$ ) le imprime al juicio de hecho una racionalidad suficiente: si una de las posturas en competencia supera como grado de confirmación el 0,5 de probabilidad de ser correcta, entonces puede aceptarse como el soporte de la decisión. Para el ámbito criminal, en cambio, el estándar suele ser mayor en razón de los intereses en juego: así, para la acusación la práctica norteamericana exige acreditar los hechos "más allá de toda duda razonable" (beyond a reasonable doubt)", mientras que para la absolución apela a un estándar de "preponderancia de la prueba" (preponderance of evidence). E incluso si miramos en detalle la posición del acusado es posible hilar más fino, según si él ha presentado una hipótesis amparada en una justificación ("una defensa cimentada en la conducta") diciendo que ciertos hechos avalan su comportamiento, el estándar aplicable será el de "más allá de toda duda razonable", o bien, en una excusa ("defensa orientada hacia el actor"), alegando que aunque su conducta es reprochable hay rasgos de su personalidad que aminoran o eliminan su responsabilidad criminal, en cuyo supuesto se aplica el mismo estándar que para las discusiones civiles, o sea, la probabilidad prevaleciente ${ }^{8}$. En cualquier caso la intuición detrás de la justicia angloamericana es la misma y debe ser recogida en Chile: la elección del estándar es un desafío ligado a los bienes en juego.

Un par de ejemplos alcanzan para graficar este punto. Si recordamos que la responsabilidad civil se define por una pugna entre la libertad (relativa) de acción y la seguridad (relativa) ante los daños, es patente que el aumento de fallos erróneos en este ámbito inci-

\footnotetext{
${ }^{1}$ STEIN (1991) pp. 133-136.

${ }^{2}$ Por todos Ormazabal (2004) pp. 125-135.

${ }^{3}$ En esta línea Accatino (2009) pp. 352, 359, Coloma (2009) pp. 211-212, Cerda (2009) p. 87, Fuentes (2011a) pp. 178-180.

${ }^{4}$ LAUdan (2006) p. 64.

5 Weinstein (1966) p. 236.

${ }^{6}$ En esto sigo la descripción de Clermont y Sherwin (2002) pp. 243 ss.

${ }^{7}$ Por ejemplo Martin v. Ohio (1987) 408 U.S. 228 citado en DamašKa (1997) p. 92 (nota 36).

${ }^{8}$ Bierschbach y Stein (2007) pp. 177-178.
} 
de directamente en el grado de seguridad que podemos esperar en nuestras relaciones, así como en la esfera de libertad que gozamos ante los demás. Para hacer posible este equilibrio entre libertad y seguridad consagrado por la norma de imputación civil (art. 2.314 del Código Civil) es preciso no errar al juzgar los hechos. Los falsos positivos (acoger una acción cuando el demandado no es responsable) y los falsos negativos (desestimarla cuando el demandado sí es responsable) son una fuente real de peligro que amenaza la armonía entre libertad y seguridad que la norma de imputación promete a los ciudadanos. Para minimizar esta amenaza una justicia civil atenta a los problemas de reparto de errores que entraña todo juicio de hecho debe contemplar una baraja de estándares sensibles a los asuntos que las partes promueven ante ella. Así, por ejemplo, para precisar si un menor murió ahogado en una piscina pública debido a los bordes resbaladizos de la misma y no por la distracción del salvavidas ${ }^{9}$, o bien, para conocer si una fumigación se hizo mientras soplaba viento sur y a escasa distancia de un predio vecino para cuyos huertos resultaba peligroso el líquido esparcido $^{10}$, -dos casos típicos de incertidumbre en la imputación civil- parece adecuado un estándar de probabilidad prevaleciente, porque en principio son igualmente valiosas las cuestiones esgrimidas por ambas partes. Y nótese que la importancia del umbral de prueba es independiente de si el problema jurídico de fondo es uno de causalidad, daño o culpa, porque la pregunta por los hechos es previa a la decisión jurídica. Un segundo ejemplo, tomado ahora del derecho sucesorio, vuelve sobre lo mismo: si alguien cuestiona la capacidad del testador para disponer de sus bienes en su testamento lo que tiene que resolver el juez es una tensión entre dos cuestiones valiosas, el respeto de la última voluntad de alguien sobre su patrimonio y la censura de actos fraudulentos de quienes pueden haber manipulado al testador. Como ocurre en parte de EEUU -Louisiana, New Jersey, Pennsylvania, Washington, por ejemplo- quizás para estos casos lo más conveniente sea un estándar de prueba clara y convincente (más intenso que el de probabilidad prevaleciente, según se dirá), porque la voluntad que se expresa en los testamentos debería ser una meta preminente para la justicia, aceptándose más falsos negativos (no sancionar a quienes forzaron al testador) que falsos positivos (revisar la voluntad del testador cuando no correspondía) ${ }^{11}$.

En palabras de la Supreme Court norteamericana en Addington v. Texas, "el estándar de prueba sirve para distribuir el riesgo de error entre los litigantes e indicar la importancia relativa adjunta a la decisión final" 12 . Con esta noticia sobre la mesa mi propósito en estas líneas es lo siguiente: (i) indagar muy escuetamente desde un plano descriptivo si los jueces civiles chilenos (entiéndase aquí jueces civiles, de familia y laborales) aplican algún estándar de prueba cuando juzgan los hechos, sea uno de convicción (objetiva o subjetiva), o uno afín al sistema tasado del Código Civil y del Código de Procedimiento Civil de 1903. Las dos observaciones que haré en este punto quedan, por cierto, condicionadas a lo que pueda arrojar un estudio de campo detenido sobre el tema. (ii) Desde un plano normativo repaso

\footnotetext{
${ }_{9}^{9}$ Corte de Apelaciones de Santiago, 1 de abril de 1999, Gaceta Jurídica, No 226, p. 84 citado en Corral (2003) p. 198.

${ }^{10}$ Corte Suprema, 27 de noviembre de 1965, Revista de Derecho y Jurisprudencia, tomo 62 (1965), sección 1a, p. 205 , cons. $16^{\circ}$ citado en Larroucau (2007) p. 112.

${ }^{11}$ Sobre esto VARS (2010) pp. 1 ss.

12 (1979) 441 U.S. 418, 423 citado en Сноо (2009) p. 48.
} 
LARroucau Torres, Jorge "Hacia un estándar de prueba civil"

las principales razones que se han ofrecido en la literatura comparada para decir que el juicio civil debe usar como regla general un estándar de probabilidad prevaleciente, a efectos de sondear si ellas son o no aplicables a la justicia chilena. Este examen sirve de antesala para luego contrastar las ventajas y defectos de dos perspectivas que se pueden adoptar sobre los estándares de prueba: (a) un enfoque externo, basado en reglas de peso probatorio y (b) un enfoque interno, amparado en la convicción del juez sobre los hechos (que se creen o se aceptan como) verdaderos. Una vez exploradas ambas tesis cierro este análisis aludiendo a la inferencia a la mejor explicación como una suerte de estrategia intermedia donde se rescatan intuiciones que provienen tanto del encuadre externo como interno en la elaboración de un estándar probatorio.

El lenguaje que habitualmente se usa para hablar sobre este puñado de temas es bastante críptico en ocasiones, por lo que (sin renunciar a su utilidad como lenguaje técnico) me esforzaré porque las ideas sobrevivan a través del uso de ejemplos. De igual forma, el que ciertas afirmaciones se reiteren un par de veces a lo largo del artículo responde a esta misma finalidad. Mi objetivo es interiorizar la idea que el estándar probatorio tiene una incidencia directa en el aumento o disminución de las sentencias erróneas en el área donde rige, de modo que un desafío apremiante para todo análisis racional de la prueba es arrimarse a delinear cada uno de los estándares (i. e., de los márgenes de errores que estamos dispuestos a tolerar) en las diversas parcelas del ordenamiento vigente.

\section{2. ¿USAN NUESTROS JUECES CIVILES UN ESTÁNDAR DE PRUEBA?}

Para la ley procesal civil implementada en los primeros años del siglo XX la pregunta por el estándar de prueba aplicable a las narraciones de las partes no fue una cuestión importante. Algo más de un siglo después tampoco hay en Chile un estudio en terreno que responda la duda que encabeza este apartado. A pesar de ello me atrevo a sugerir en forma tentativa dos rasgos de nuestra práctica judicial a los que deberíamos prestar más atención: (a) por una parte, parece que los jueces civiles perciben la libre valoración de las pruebas (o sana crítica como dice nuestra ley procesal hoy) como un rechazo a las reglas de peso probatorio y un aliciente para que determinen según su convicción (en clave subjetiva) si los hechos están o no probados; (b) por otro lado, el actual reparto de competencias en la administración de justicia incide en que un juez aplique el estándar de prueba penal ("más allá de toda duda razonable") a las disputas civiles. Respecto de lo primero es muy ilustrativa una opinión de nuestra Corte Suprema citada por Emilio Rioseco sobre los alcances de la libre valoración:

"La sana crítica es aquella que nos conduce al descubrimiento de la verdad por los medios que aconseja la recta razón y el criterio racional puesto en juicio. Es analizar sinceramente y sin malicia las opiniones expuestas acerca de cualquier asunto. Las reglas que la constituyen no están expuestas en la ley. Se trata de un proceso intelectual 
interno y subjetivo, o sea, es materia de apreciación y por lo mismo de hecho, que corresponde exclusivamente a los jueces del fondo". ${ }^{13}$

Esta lectura sintoniza con el postulado benthamiano de que la valoración de las evidencias no comulga con reglas tasadas de peso probatorio ${ }^{14}$. Por el contrario, el apelativo a un "proceso intelectual interno y subjetivo" es el típico lenguaje cognitivo utilizado por nuestra jurisprudencia para justificar un juicio de hecho en términos de convicción o credibilidad. Kevin Clermont ha sugerido que en el proceso judicial del sistema continental se acude a un estándar de "íntima convicción" o "convencimiento moral” como una estrategia de legitimación del servicio judicial, en la medida que al ofrecerles a los ciudadanos una certeza sobre los hechos (en lugar de una 'mera probabilidad') invocando la verdad del caso se logra la confianza de una comunidad históricamente reticente ante el poder de los tribunales. El estándar de convicción sería confortable para nuestros jueces civiles en la medida que "les brinda una roca donde parapetarse". Sea o no una tesis correcta, lo cierto es que entre los inconvenientes que asedian al estándar subjetivo -sobre los cuales no me detengo ahora- se cuenta una amenaza no menor: este umbral inclina la balanza hacia los falsos negativos porque incentiva a los jueces a emplear el mismo estándar de los juicios criminales en temas civiles ${ }^{15}$. Este segundo punto, como deslicé antes, se ha materializado en casos de responsabilidad cuando la víctima ventila su pretensión indemnizatoria en el proceso criminal. En estas situaciones no es extraño que los jueces usen el estándar penal para juzgar los hechos de un asunto civil como la indemnización. Ello es un problema grave porque traslada el reparto de los riesgos del derecho criminal fuera de su marco de justificación. Un ejemplo patente de esta distorsión en el juicio de hecho lo entrega Olivares con Zuleta:

"Si bien el resultado dañoso se produjo, no aparece de los antecedentes agregados al proceso cuál fue específicamente la conducta, y qué persona del amplio equipo de profesionales que intervino en la operación quirúrgica de la menor lesionada la desarrolló, que haya ocasionado dicho resultado lesivo [Luego] al sentenciador le asiste la duda razonable de que haya sido el actuar de la pabellonera acusada en autos, la causa precisa y necesaria de las lesiones con que resultó la menor Silvia Marchant Flores; no arribando de esa forma a la convicción que exige el artículo 456 del Código de Procedimiento Penal para condenar" (cons. 10).

Por ende,

"se rechazará en todas su partes, la demanda civil interpuesta en el primer otrosí de fs. 285 , tanto por la parte querellante como por la parte de la actora civil, en atención a que conforme se ha razonado precedentemente no se ha establecido res-

\footnotetext{
${ }^{13}$ Corte Suprema, $1^{\circ}$ de abril de 1974, Revista de Derecho y Jurisprudencia, tomo 68 (1971), sección 1aa, p. 76 citado en Rioseco (1995) t. II No 694 p. 378.

${ }^{14}$ Bentham (1825).

${ }^{15}$ Clermont (2009) pp. 471-473.
} 
ponsabilidad penal de la acusada Rosa Zuleta Vega, en el ilícito culposo materia de la acusación, lo que elimina, asimismo toda responsabilidad civil extracontractual solidaria" (cons. 190). ${ }^{16}$

En Olivares el tribunal no hizo otra cosa que homologar los estándares de corroboración penal y civil cuando desechó la pretensión indemnizatoria. Con ello pulverizó los márgenes de errores que estamos dispuestos a aceptar para imponer responsabilidad civil, blindando al demandado de los riesgos de errores mediante el estándar penal.

Si miramos esta práctica desde el punto de vista del sistema jurídico, el uso inadecuado de los diversos estándares de prueba supone un desincentivo para que las conductas de los ciudadanos se ajusten a lo prescrito por nuestras reglas ${ }^{17}$. Por ello me parece sensato remarcar que los estándares de prueba son algo más que "frases o expresiones elegantes" 18. La diferencia entre el modelo continental y el Common Law estriba en este punto en una cuestión normativa sobre balance de costos y beneficios: mientras la justicia civil del sistema continental boga por los beneficios ("legitimar el trabajo de los tribunales"), la segunda se preocupa de los costos ("equivocarse en el fallo") ${ }^{19}$. Es precisamente esta disparidad de enfoques lo que se observa en la justicia laboral chilena posterior a la reforma de 2006, en el juicio de tutela por violación de derechos ("fundamentales") no laborales (o "inespecíficos"). En este juicio el actor únicamente debe aportar una 'chispa' de prueba para que se acoja su relato ("de los antecedentes aportados por la parte denunciante resulten indicios suficientes", art. 493 Código del Trabajo), de modo que una vez que se despierta en el tribunal la "sospecha razonable" de que han ocurrido los hechos tal como ha relatado el trabajador ${ }^{20}$, el juez laboral está autorizado para acoger su demanda inmunizándolo de los errores en el veredicto. No dudo de que puedan haber buenas razones para repartir así los riesgos en materia laboral, pero lo que ahora me interesa remarcar es que ese estándar de prueba responde a la lógica continental de los beneficios ("acoger los reclamos de atentados a ciertos derechos fundamentales del trabajador"), sin preocuparse de justificar el reparto de costos que conlleva ("¿por qué debemos cargar a los empleadores con los gastos de una sentencia errónea?").

Para evitar estas distorsiones en nuestros litigios civiles e iniciar una mejor comprensión del juicio de hecho conviene señalar que la pregunta por el peso de las pruebas en sede civil sí puede zanjarse acudiendo a reglas probatorias. Nuestra Corte Suprema ha dejado bastante en claro "que el artículo 1.698 solamente determina a quién corresponde el peso de la prueba y fija los medios de prueba; pero el artículo no da normas para ponderarla" 21 . El onus probandi (i. e., la carga de la prueba como una regla de actividad) responde solo a

\footnotetext{
16 Juzgado de Letras de Iquique, 29 de septiembre de 2001, Rol No 15939-6, LegalPublishing No 26334 (redacción del Juez Pablo Muñoz), un análisis más detenido en Larroucau (2011) pp. 505-517.

${ }^{17}$ Ferrer (2010) p. 18.

18 Nieva (2010) p. 90.

${ }^{19}$ ENGEL (2009) p. 438.

${ }^{20}$ Ugarte (2009) p. 223.

${ }^{21}$ Corte Suprema, Revista de Derecho y Jurisprudencia, tomo 34 (1937), sección 1a, p. 521 citado en Díez (1997) p. 15.
} 
la duda acerca de quién debe aportar información al juicio, abaratando los costos de un tribunal que precisa de antecedentes para juzgar los hechos, pero nada dice sobre asignarle mérito a esos datos. O sea, la carga de la prueba es conceptualmente diferente de cualquier estándar probatorio (i.e., la carga de la prueba como una regla de juicio), aunque en el día a día de los juicios ambas categorías se aproximen (porque las partes suelen decidir sus cartas probatorias según lo que ellas piensan que el tribunal hará si la evidencia es o no presentada) ${ }^{22}$. Después de ciento cincuenta años de soledad del art. 1.698 del Código Civil $^{23}$, una regla ocupada de la actividad probatoria, debemos orientar el debate procesal hacia los estándares como regulación del resultado de la prueba. Este giro se torna inevitable bajo un modelo de valoración libre de las prueba, donde la esperanza de que el juez consiga una versión (tenida por) verdadera del caso $^{24}$, se ve en aprietos si ambas partes ostentan, como habitualmente ocurre en disputas patrimoniales, antecedentes a favor y en contra de sus relatos. El derecho comparado, sobre todo el debate angloamericano, nos ofrece varios candidatos para abordar este escenario.

\section{EN UNA ESCALA DE 0 A $1 \ldots$}

Para la justicia civil angloamericana el estándar de probabilidad prevaleciente o regla de P>0,5 ocupa un lugar de privilegio como umbral de prueba. La razón es bien simple: garantiza una distribución igualitaria de los riesgos de errores entre actor y demandado (vistos ellos no como sujetos aislados, sino como clases de litigantes). En palabras ligeramente distintas, porque minimiza el número de veredictos erróneos de manera igualitaria entre las partes: los falsos positivos (aceptar la pretensión del actor cuando no corresponde) y los falsos negativos (no dar lugar a la pretensión cuando sí procedía) son igualmente indeseables. Desde la óptica inversa, por tanto, el estándar de probabilidad prevaleciente maximiza las decisiones correctas en el trabajo judicial, otorgándole un soporte de justicia (fairness) y eficiencia para ser considerado el mejor candidato a estándar en sede civil ${ }^{25}$. La regla de $\mathrm{P}>0,5$ no solo proporciona un trato indiferenciado a las partes, sino que al mismo tiempo se hace cargo de los limitados recursos de que dispone un tribunal: así, "la minimización de errores del estándar de preponderancia sirve mejor a la verdad"26, pues impide que un relato basado en hechos verdaderos sea finalmente descartado porque no satisfizo una exigencia probatoria excesiva. De igual manera, si queremos que la justicia civil se vuelva menos costosa, podemos incrementar el estándar el estándar de prueba por sobre 0,5 para que así disminuyan los fallos estimatorios, que son los que obligan al (costoso) ejercicio de imponer sanciones ${ }^{27}$.

\footnotetext{
${ }^{22}$ HaY y Spier (1997) pp. 415-416.

${ }^{23}$ Art. 1698 Código Civil: "Incumbe probar las obligaciones o su extinción al que alega aquellas o estas. (2) Las pruebas consisten en instrumentos públicos o privados, testigos, presunciones, confesión de parte, juramento deferido, e inspección personal del juez".

${ }^{24}$ Cfr. Taruffo (1992) y Gascón (1999).

${ }^{25}$ Véase Porat y Stein (2001) pp. 18-42, Stein (2005) pp. 143-149.

${ }^{26}$ Clermont y Sherwin (2002) p. 271.

${ }^{27}$ Kaplow (1994) pp. 356-362.
} 
¿Son suficientes estas razones para que en los procesos civiles en Chile nos guiemos por un estándar de probabilidad prevaleciente? Por mi parte creo que sí, en el sentido que "si la evidencia es tal que el tribunal pueda decir 'pensamos que es más probable a que no', entonces la carga ha sido cumplida”, como dijo Lord Denning en Miller v. Minister of Pensions, el fallo clásico de la jurisprudencia inglesa ${ }^{28}$. Esta inclinación, por supuesto, no nos libera de repensar críticamente las razones que fundamentan dicho estándar. Así, por ejemplo, me parece que lo observado por David Kaye en cuanto a que lo que minimiza en definitiva este estándar son los riesgos de pérdidas que se espera que ocurran al equivocarse el juez, puede ser de utilidad en el diseño de los juicios civiles. Esto por dos razones. Primero, porque en ese caso lo que consigue el estándar es que las personas evalúen en mejor pie si van a juicio (y en qué términos) y, segundo, porque nos muestra que un error judicial nunca podrá ser compensado con otro error judicial, del modo en que la idea tradicional del "reparto igualitario" desea sugerir. Por así decirlo, aunque ambos errores "valen lo mismo" (en tanto son igualmente costosos), nunca se compensan unos con otros. La justicia no pretende igualar los errores de la prueba, sino que se propone reducirlos en términos agregativos $^{29}$.

Pensar en la administración de justicia como un servicio público nos da una perspectiva útil para desafiar la regla $\mathrm{P}>0,5$ con un puñado de preguntas del siguiente tenor: (i) ¿Es coherente este umbral con el hecho que el juicio civil no cargue a los litigantes con los costos (regla de gratuidad) o con la desigual información que tienen sobre el caso?30 (ii) Dado que cualquier estándar de prueba entraña imponer otro estándar complementario a la contraparte (reducir el riesgo de uno es incrementar el riesgo del otro) ${ }^{31}$, ¿¿debemos fomentar el statu quo en las discusiones patrimoniales mediante el estándar de prueba? Como se ha podido ver, la regla $P>0,5$ inclina mínimamente los riesgos sobre el actor porque si no supera ese umbral su relato será desestimado en el juicio. Y aunque hay razones plausibles para ello (como desalentar los juicios en casos dudosos, incentivando a que las personas ponderen mejor los costos de la incertidumbre del caso) ${ }^{32}$, el estándar de probabilidad prevaleciente, aunque se vista como una regla igualitaria, de alguna manera protege el actual estado de cosas. (iii) En los escenarios donde el estándar no sirve para reducir los riesgos de error porque la evidencia resulta escasa o es de baja calidad, ¿provee al menos de un incentivo para maximizar un comportamiento adecuado en los litigantes? ${ }^{33}$ Piénsese en los juicios de responsabilidad extracontractual. La regla $\mathrm{P}>0,5$ permite leer los accidentes no solo en términos de un estándar de cuidado (“quién es culpable del accidente?”) sino que también a la luz del resultado de la prueba ("es relativamente más probable que las pruebas se acepten únicamente cuando se quebrantó la regla de imputación y que no lo sean cuando dicha regla fue cumplida”). Lo mismo explica una típica regla de exclusión de prueba: las

\footnotetext{
28 (1947) 3 All Er 372 citado en Redmayne (1999) p. 168.

${ }^{29}$ Cfr. Kaye (2003) pp. 9-13.

30 SANCHIRICO (1997) pp. 431 ss.

${ }^{31}$ Harmer (2004) pp. 73-74.

32 Zuckerman (1994) p. 359 (nota 12).

33 Fluet y Demougin (2005) pp. 200-207.
} 
relativas al carácter del demandado, porque si toda evidencia es una señal sobre una acción, entonces son irrelevantes los testimonios ex ante sobre el tipo de ofensor ha demandar. Así, el umbral 0,5 optimiza la disuasión en la sociedad al incrementar los comportamientos en conformidad al debido cuidado civil por la vía de aumentar las probabilidades de que el tribunal solo impute responsabilidad cuando el acto ha sido realmente cometido ${ }^{34}$.

Con todo, aunque el estándar de prueba de la probabilidad prevaleciente parece resistir bien estos embates, hay ciertas ocasiones en que la escala de 0 a 1 merece ser inclinada. Ello tiene que ver con las expectativas de un determinado sector del tráfico jurídico. Nótese que la pluralidad de estándares probatorios viene a ser un rasgo característico de un sistema de administración de justicia civil refinado, capaz de identificar los diferentes umbrales que reclaman los conflictos que se ventilan por vía judicial ${ }^{35}$. Por ejemplo, en los juicios donde la secuela para la demandada no es solo jurídica (un fallo judicial desfavorable), sino que también social, como ocurre en la litigación por fraude, o bien, en litigios donde se comprometen las libertades civiles (deportaciones, declaración de interdicción de un familiar, remoción de una licencia médica), así como en las disputas sobre relaciones parentales, la regla $P>0,5$ no es satisfactoria. Para estos casos se acude a lo que en la justicia civil norteamericana se denomina un estándar intermedio de "evidencia clara y convincente" o regla $P>0,75$. El motivo para intensificar el umbral en estos juicios es el mismo que justifica para los restantes procesos la regla $\mathrm{P}>0,5$ : la igual consideración y el debido respeto por los intereses en juego justifica acentuar la dirección de los riesgos hacia el actor. Un caso conocido para quienes se interesan por la responsabilidad civil graficará este punto: Masson v. New Yorker Magazine, Inc. ${ }^{36}$ una demanda indemnizatoria fruto de una publicación que afectó la reputación de un funcionario público. Como las reglas de responsabilidad resguardan la libertad de expresión para los casos en que el posible afectado no es un ciudadano común y corriente elevando el criterio de imputación de negligencia a dolo, el tribunal uso para evaluar el resultado de la prueba el umbral de $\mathrm{P}>0,75$, depositando así los riesgos de error sobre el actor (la persona difamada) e inmunizando de paso al New Yorker. Un reparto del riesgo en sentido inverso habría exigido, en palabras de Ronald Dworkin, "una determinación colectiva de que hay un mayor perjuicio [moral harm] en sufrir una calumnia falsa y no compensada, que en ser condenado en daños por una difamación en los hechos verdadera" 37 .

En Inglaterra este aumento en el umbral se ha logrado mediante un estándar intermedio entre el civil y el criminal -llamado "Higher Standard of Proof"- frente a conductas que, teniendo una sanción penal, se ventilan dentro de un litigio civil. Por ejemplo, cuando un banco demanda de responsabilidad civil a un empleado por haber robado dinero. Si bien a primera vista pareciera que la regla $\mathrm{P}>0,75$ rige debido a la seriedad de la acusación ("el empleado no fue descuidado, sino que robó el dinero"), en estricto sentido el umbral se eleva por la gravedad del resultado y no del relato. Esta seriedad de las consecuencias es

\footnotetext{
${ }^{34}$ LANDo (2002) p. 603.

${ }^{35}$ Anderson, Schum y TwinIng (2005) pp. 242-244.

36 (1991) 501 U.S. 496, 510 citado en STEIN (2008) p. 82.

${ }^{37}$ Dworkin (1981) p. 89.
} 
lo que exige del juez civil un "escrutinio acabado" (anxious scrutiny) de las circunstancias, o bien, una "prueba contundente" (cogent evidence) de los hechos ${ }^{38}$. La misma lógica se puede observar en la justicia chilena de familia cuando conoce de juicios de divorcio por culpa Zattera con Bancalari, por ejemplo- ${ }^{39}$, juicios donde se conecta el relato de la demandante con la gravedad que acarrearía para el demandado el que se acoja esa historia. Pero colocar cuesta arriba la escala probatoria tiene un impacto no menor en las pretensiones de quien obra como demandante. Por ello, como ha señalado Mike Redmayne, el estándar de probabilidad prevaleciente o regla $\mathrm{P}>0,5$ en la litigación civil "debe ser protegido por algún grado de inercia" ${ }^{40}$, de modo que el juez únicamente se aparte de él con buenas razones. Esta posibilidad de inclinar la escala en los juicios civiles nos invita en último término a cuestionar la vigencia del argumento que durante años ha dicho que el estándar civil es menos exigente que el criminal debido a los bienes en juego. No solo la severidad de las penas se ha racionalizando (derogando la pena de muerte y las penas corporales), sino que las secuelas de una sentencia civil errónea también pueden ser "ruinosas para un individuo" ${ }^{1}$, una dimensión que este estándar intermedio de prueba clara y convincente captura con nitidez.

Lo expuesto en los párrafos anteriores pone de manifiesto que los estándares de prueba en sede civil son tratados en el lenguaje de las probabilidades. Pero no es menos cierto que en la práctica esta escala de 0 (ignorancia) a 1 (conocimiento) no ha podido satisfacer todo lo que esperamos de los tribunales cuando juzgan los hechos. Resulta suficiente un grado de probabilidad superior a 0,5 (o superior a 0,75) para juzgar una narración: "hace falta algo más” ${ }^{2}$. Esta pieza adicional puede ser, como veremos en la segunda parte de este artículo, la convicción del juez sobre la verdad de los hechos o la aplicación de una regla de peso probatorio. $\mathrm{O}$ incluso ambas, como parece sugerir la inferencia a la mejor explicación al cultivar intuiciones tanto 'desde dentro' como 'desde fuera' del juicio.

\section{DOS ENCUADRES DEL ESTÁNDAR DE PRUEBA CIVIL}

Una forma de explorar la aplicación de los estándares de prueba se encarga de distinguir dos perspectivas: (i) un enfoque externo, basado en reglas legales de peso probatorio y (ii) un examen interno, amparado en la convicción del juez civil sobre la verdad de los hechos. Los dos encuadres ameritan un análisis que los considere en sus mejores versiones. Comienzo con la primera de estas estrategias, las reglas de peso probatorio. Estas normas pretenden un juicio de hecho justo y eficiente por la vía de introducir una jerarquía entre las múltiples fuentes de información que en su momento valorará el juez. Para investigar si este objetivo es o no posible conviene disociar dos nociones de peso:

\footnotetext{
${ }^{38}$ Macbride (2009) p. 341.

39 Corte de Apelaciones de Concepción, 09 de junio de 2010, Rol No 423-09, cons. $8^{\circ}$ citado en Fuentes (2011a) p. 199 y Juzgado de Letras Garantía y Familia de Chanco, 07 agosto 2006, RIT 22-06 citado en Fuentes (2011b) pp. 137-138, 141.

40 Redmayne (1999) pp. 174, 187.

${ }^{41}$ DamašKa (1997) pp. 120-121.

${ }^{42}$ Harmer (1994) pp. 509-512.
} 
"En un sentido amplio, el peso simplemente alude al valor probatorio o validez predictiva de cualquier clase relevante o pieza probatoria al realizar un juicio probabilístico. En este sentido, se puede hablar inteligiblemente de la necesidad de dar un peso apropiado a la base de datos al formular ciertas predicciones o acordar un peso adecuado a la evidencia circunstancial en un juicio [...]. Pero el peso en un sentido restringido se refiere a la confiabilidad de la prueba directa de algo. Esto es, mide cuán confiable es que algo que se propone mostrar cuando $\mathrm{X}$ es verdadero o cuando $\mathrm{X}$ ocurre es en realidad probativo de que $\mathrm{X}$ es verdadero o que $\mathrm{X}$ ocurre. El peso en este sentido describe la relación entre la declaración de un testigo y los hechos sobre los cuales el testigo depone". 43

Esta diferencia es relevante porque en su sentido acotado la noción de peso se hermana con las presunciones. La única diferencia es que la regla de peso se aplica al testimonio directo mientras que la presunción está pensando en una prueba de corte circunstancial. Pero si las presunciones son actores habituales en la adjudicación, ¿qué problema habría con incorporar al juicio reglas de peso probatorio? Para trazar una respuesta a esta duda es preciso recordar algo que ningún análisis de la prueba está dispuesto a controvertir: lo que llamamos evidencia directa -como la declaración de un testigo presencial de los hechos- depende en sí misma de generalizaciones, pues los testigos filtran sus observaciones del caso en base a sus propios sesgos, prejuicios y preconcepciones. De allí que estructuralmente una prueba directa no difiere de una evidencia circunstancial ${ }^{44}$. Tomando esto como punto de partida, las reglas de peso probatorio no tendrían que ser repelidas por un modelo de libertad en la valoración de pruebas por hacer lo mismo que las abundantes presunciones en sede civil, es decir, "describir la relación" entre la prueba y el hecho, mostrándonos su confiabilidad. La pregunta crucial es si podemos incluir en un modelo de libertad reglas de peso en su dimensión amplia, o sea, reglas que articulen una "sensibilidad más que mínima" en el reparto de los riesgos de error ${ }^{45}$, prescribiéndole al tribunal la "validez predictiva de cualquier pieza probatoria”.

Para asediar esta última posibilidad el trabajo de Alex Stein, en especial Foundations of Evidence Law donde cristalizan dos décadas de investigación, es un referente obligado. Para Alex Stein el juicio de hecho colaciona dos dimensiones, probabilidad y peso, que se entremezclan en cada juicio, por lo que un estándar de probabilidad como la regla $\mathrm{P}>0,5$, en tanto ha marginado la noción de peso, no puede explicar de forma adecuada la distribución racional de los riesgos de error que dice perseguir ${ }^{46}$. La valoración de las pruebas debe hacerla el juez a la luz de una lectura integradora, distinguiendo

"entre la probabilidad de los hechos litigados y la suficiencia probatoria o peso que marca cada juicio probabilístico. La probabilidad está determinada sobre la base de la

\footnotetext{
43 Barzun (2008) p. 1990.

44 Véase Schauer (2003) pp. 92-107.

${ }^{45}$ BAYÓN (2008) p. 9.

${ }^{46}$ Cfr. STEIN (1996) pp. 299-300 y (2005) pp. 80-91.
} 
LARroucau Torres, Jorge "Hacia un estándar de prueba civil"

prueba existente, sin ser afectada por la amplitud, o la resiliencia, de su base probatoria subyacente, que depende de la extensión de la investigación judicial [El peso, por su parte], refiere a la suficiencia de la prueba sobre la cual el juicio de probabilidad es formulado [...] Las decisiones sobre esto último, i. e., las decisiones acerca de la suficiencia de la prueba para emitir el veredicto, no son decisiones probabilísticas [...] La prueba no tiene peso per se; solo los argumentos desde la prueba, que mueven el proceso inferencial hacia adelante, son los que pueden tener mayor o menor peso, dependiendo de la amplitud de su base probatoria". ${ }^{47}$

Este marco es interesante porque nos permite identificar por lo menos tres aproximaciones al estándar de prueba que terminan en una explicación arbitraria (o discrecional) del juicio de hecho:

(1) La "aproximación ficticia”, según la cual la recopilación de las pruebas proporciona al juez una imagen completa del caso. Esta tesis no hace sino imponer limitaciones artificiales al juicio de hecho porque, como ya se dijo, la información disponible en un litigio es siempre parcial, no exhaustiva, de modo tal que no resulta sensato decir que una vez terminada la discusión la prueba disponible da una imagen acabada del caso ${ }^{48}$;

(2) La "aproximación contra-fáctica", según la cual el juicio de hecho puede modificarse al añadir o restar datos al proceso. Nótese que esta es una idea correcta (el juicio de hecho es relacional: depende siempre de la información recopilada), pero no entrega una buena explicación del estándar de prueba porque avala la existencia de diferentes respuestas a un mismo caso por el solo hecho de cambiar al juez, aunque las competencias (epistémicas) de ambos jueces sean iguales. Esta es una de las tesis más atractivas del giro racionalista de la prueba hacia un modelo de libertad -los hechos dependen de las evidencias recabadas-, pero que paradójicamente nos muestra que el asunto de fondo es normativo. Pretender que "si otro juez no hubiese aceptado (o descartado) esa pieza de información el resultado sería distinto" es una explicación insuficiente del estándar de prueba. Enfrentar así la pregunta por los hechos probados equivale a "autorizar a los jueces para 'apostar' por sus indagaciones ad hoc" ${ }^{49}$, lo que deposita el éxito o fracaso del juicio de los hechos en un lugar que no queremos: en la persona del juez;

(3) La "aproximación de la 'máquina expendedora" ('slot-machine') pretende resolver esta circunstancia (epistémica) de que nuestros juicios muestran una apertura constante hacia dos "mundos posibles" (lo que se hizo y lo que se pudo hacer) echando mano al onus probandi. Esta estrategia goza de muy buena salud dentro del sistema continental ${ }^{50}$, pero adolece del mismo defecto que las dos anteriores: depende de la discrecionalidad del juez. Nótese que si el tribunal no tiene claridad sobre lo ocurrido porque hay datos a favor y en contra de ambas historias, es arbitrario desde el punto de vista epistémico zanjar el caso

\footnotetext{
${ }^{47}$ STEIN (1997) pp. 581-582.

48 STEIN (1996) pp. 312-313.

${ }^{49}$ STEIN (1996) p. 314.

${ }^{50}$ Por todos Taruffo (2009) pp. 254-266.
} 
contra el litigante que tiene el onus probandi. Desde la perspectiva epistémica no hay razones válidas para asumir que un relato (que no ha conseguido prevalecer sobre el otro) debe ser perjudicado por la circunstancia de que la persona que lo esgrime tiene la carga de aportar evidencias cuyo valor para dicho caso todavía se desconoce.

La mirada 'desde fuera' del juicio de hecho nos muestra que hablando solo de hechos probables la pregunta sigue en pie. ¿Cómo inclinamos la balanza si ambas narraciones gozan de elementos a favor? Ya se sabe que en sede criminal la respuesta (normativa) es la presunción de inocencia ${ }^{51}$, pero en materia civil parece que todavía carecemos de una alternativa con el mismo nivel de aceptación. Lo que sí deberíamos aceptar en sede civil es el rechazo a las respuestas arbitrarias o discrecionales de los tribunales. Una valoración libre de la prueba ("tesis de la separación") que cercena probabilidad y peso parece inadecuada porque supone un reparto no controlable de los riesgos de error. Para acercarnos a una respuesta positiva a la pregunta sobre cómo inclinamos la balanza Alex Stein ha propuesto que todos los momentos de la prueba se delineen en conformidad "a principios jurídicos y/o reglas que puedan proveer una distribución del riesgo de error en forma explícita, autoritativa y exhaustiva" 52 . O sea, reconocer que el Derecho de Prueba moderno está sembrado de temas normativos. Para avanzar bajo este horizonte en el momento de la valoración traza algunas pistas: (a) atendiendo a que las indagaciones judiciales se materializan en apuestas que hacen los sujetos procesales por algunas estrategias probatorias en desmedro de otras, las que supongan riesgos inaceptables deben ser rechazadas ab initio (por ejemplo, excluyendo todos los datos que dan auge a indagaciones impropias); y (b) si existe una línea de investigación favorable para conocer el caso, todas las pruebas que se enmarca dentro de ella serán preferentes y tienen prioridad por sobre las evidencias que conducen a otras indagaciones que suponen riesgos inaceptables (por ejemplo, si un litigante frustra una investigación útil cabe una inferencia probatoria contra sus intereses). Para la "tesis integradora" de probabilidades y peso hay, en último término, dos formas de repartir el peligro de un fallo equivocado: una cuantitativa, que pasa por identificar diferentes requisitos de corroboración según sea los temas que conozca la justicia civil; y otra cualitativa, estableciendo estándares de prueba que demanden más especificidad con respecto a las informaciones que se usan para juzgar las probabilidades en cada uno de aquellos casos.

Ahora bien, a pesar de su atractivo, las reglas de peso probatorio hallan en la convicción del juez civil un poderoso rival cuando se trata de sentar ese algo más que permite tener por probados hechos que son probablemente ciertos. Este enfoque interno tiene en Chile el auxilio del art. 428 del Código de Procedimiento Civil, que ordena a los jueces inclinarse por la prueba "que crean más conforme a la verdad" y suele hacerse explícito a nivel comparado, por ejemplo, en los Principles of Transnacional Civil Procedure (que apelan a un tribunal "razonablemente convencido de la verdad") 53 y especialmente en la Zivilprozessordnung alemana (donde lo que se exige es un "libre convencimiento" para "considerar una

\footnotetext{
${ }^{51}$ LAUDAN (2006) pp. 82-83.

52 STEIN (1996) pp. 320-321.

${ }^{53}$ Art. 21.2 Unidroit: "Facts are considered proven when the court is reasonably convinced of their truth".
} 
manifestación de los hechos como verdadera o falsa" ${ }^{54}$. Creo que uno de los trabajos que mejor permiten indagar la relevancia del enfoque interno del estándar es el desarrollado por Hock Lai Ho en A Philosophy of Evidence Law. Justice in the Search for Truth, quien precisamente se hace cargo de examinar el estándar de prueba desde el doble prisma, externo e interno, que antes he mencionado ${ }^{55}$. Para aquilatar el aporte de Ho es preciso detenerse primero en las tres lecturas que admite un estándar de prueba desde la acera externa:

(1) Como el "terminal" (end-state) de la valoración de las pruebas, el estándar informa al sistema jurídico acerca del grado de confianza en la verdad que tiene una hipótesis que ha sido corroborada, pero sin que importe mirar el camino seguido para alcanzar ese punto;

(2) Como un "umbral decisorio" (decisional thresholds), donde el estándar probatorio tiene dos formas de operar: (a) una función "por defecto" (default), ante la incertidumbre sobre los hechos y la imposibilidad de decir "no lo sé" (regla de inexcusabilidad) el juez encuentra en el estándar su regla de desempate (tie-breaker); aunque para Ho estos casos resultan ser excepcionales ya que únicamente en los juicios difíciles se activa la función "por defecto", la que sería una modalidad contingente del estándar de prueba. En cambio, (b) la función regulatoria presenta al estándar como el grado mínimo que se exige para inclinarse por un relato en desmedro de los demás: un punto de referencia (benchmark) contra el cual el tribunal mide su confianza en cada narración. Ho piensa que desde el punto de vista externo esta función regulatoria está siempre presente, haciendo del estándar un punto fijo y determinado, aunque los casos litigados difieran entre sí;

(3) Como un "supuesto metodológico" del nivel donde nuestro ordenamiento jurídico clava el umbral para resguardar los bienes que le interesan y conseguir los objetivos que espera de la justicia. Esta lectura, más que ninguna otra, reivindica la construcción del estándar de prueba en los procesos judiciales como una tarea de corte normativo o político.

Frente a esta reflexión externa es que Hock Lai Ho presenta una mirada 'desde dentro' de la tarea judicial. Este encuadre interno ofrece una nueva tríada donde es la convicción del juez aquello que permite discriminar entre hechos con un grado de probabilidad. Bajo este enfoque interno el estándar de prueba puede ser visto de las siguientes formas:

(1) Como una pieza centrada en el proceso judicial mismo (y no en su estado terminal), que habilita al juez para hacerse cargo de las pruebas rendidas y dar una adecuada justificación del valor que provisionalmente les asigna a cada una de ellas al admitirlas a juicio;

(2) Como una instrucción que la ley procesal entrega al juez acerca de una determinada actitud deliberativa (y no como umbral decisorio) que debe cultivar cuando examina

\footnotetext{
54 S 286 (1) ZPO alemán: "El tribunal tiene que decidir de acuerdo con su libre convencimiento teniendo en cuenta el contenido íntegro del proceso y el resultado de la realización de las pruebas, para así considerar una manifestación de los hechos como verdadera o falsa”, Cfr., Código Procesal Civil Alemán (ZPO), traducción de Juan Carlos Ortiz y Álvaro Pérez Ragone, Konrad Adenauer Stiftung, Programa Estado de Derecho para Sudamérica, Montevideo, 2006.

${ }^{55}$ Ho (2008) pp. 182-183, 185.
} 
las evidencias. El estándar ya no es un punto fijo -como si fuera "un sastre obstinado que solo usara tres medidas para todos sus clientes"-56, sino un marco de referencia que depende del tipo de conflicto promovido;

(3) Como una expresión de principios de corte epistémico que se encuentran "enraizados en una visión de la justicia en tanto cuidado empático", en donde lo que importa es el debido respeto del juez por las personas que deciden judicializar sus conflictos (y no como instrumento de política social). El estándar de prueba -este es el punto fuerte de Ho- proporciona un "estándar de prudencia" (standard of caution) al tribunal al pedirle una actitud proposicional concreta en atención a la gravedad y las consecuencias de juzgar un hecho como cierto. Bajo esta luz, el estándar garantiza una flexibilidad suficiente para adaptarse a todos los asuntos litigiosos que conocen los tribunales ${ }^{57}$, mediante una actitud deliberativa del juez que se define por tratar de igual forma los relatos de las partes. En sede civil el juez se enfrenta a los relatos como inconsistentes o contradictorios en igual grado, a diferencia del ámbito penal donde reconocemos una "protección" de la narración del acusado al presumirle su inocencia. Nótese que en el argumento de Ho la única diferencia entre el estándar civil y el penal descansa en la distribución de la prudencia requerida, pero en ambos casos el estándar posee un fundamento moral: el debido respeto por la persona contra quien se han establecido los hechos.

Esta mirada 'desde dentro' del juicio de hecho tiene la ventaja de que a primera vista sintoniza con lo que en la práctica hacen los tribunales, al menos en el marco angloamericano. Así, por ejemplo, en Schechter v. Klanfer, un caso de responsabilidad debido a un accidente que le causó al actor amnesia, entre otras secuelas, la falta de memoria fue tomada en cuenta por la justicia de New York como un argumento para imponerle al demandante civil un estándar de prueba menos exigente ${ }^{58}$. Esta misma distribución de la prudencia judicial según las circunstancias del caso se refleja en otra demanda de responsabilidad civil, ventilada ante la justicia inglesa, donde el tribunal dispuso que

“entre más seria la alegación es menos probable que el hecho ocurriese y, por tanto, más robusta debe ser la prueba antes que el juez concluya que la alegación se encuentra establecida sobre el balance de las probabilidades. Usualmente el fraude es menos probable que la negligencia. El daño psíquico deliberado es habitualmente menos probable que el perjuicio psíquico accidental [...] Incorporar el estándar de probabilidad preponderante supone un generoso grado de flexibilidad en respeto de la seriedad de la alegación”. ${ }^{59}$

Para recapitular, si bien ambos encuadres del estándar de prueba parten de un presupuesto común -el juicio de hecho es probabilístico-, se distancian en cómo ellos entienden

\footnotetext{
${ }^{56}$ La imagen es de Kirchmann (1847) p. 38.

${ }^{57} \mathrm{Ho}(2008)$ pp. 215, 223.

58269 N.E.2d 812 (1971) citado en KaYe (2003) p. 12.

${ }^{59}$ In re H [Minors] (1996) 2 WLR 8, 23, 24 citado en Сноо (2009) p. 52.
} 
al estándar en tanto la pieza adicional que divide entre lo probado y lo no probado. El enfoque interno se encuentra más cómodo pensando que los estándares entregan al tribunal un método, no un resultado ${ }^{60}$. Por ello que sobre todo los sistemas judiciales del área continental tienden a interpretar el estándar civil de probabilidad prevaleciente en clave no estadística ${ }^{61}$, bajo la idea de que algo está probado si es "más probable que esos hechos sean verdaderos a que no lo sean" ${ }^{\prime 2}$. Y en la jurisprudencia chilena este enfoque interno (a menos que un estudio en terreno indique algo diferente) parece ser el que predomina. Así, por ejemplo, cuando la Corte de Apelaciones de San Miguel rechaza la demanda de responsabilidad que interpone un paciente porque no se acreditó "con probabilidad lindante en la certeza que el resultado fue producido por la violación del deber de cuidado profesional" 63 , lo que le informa es que no basta con esgrimir hechos probables: es necesario que el juez se convenza de que lo dicho verdaderamente ocurrió.

¿Pero acaso las reglas de peso probatorio del Código Civil y del Código de Procedimiento Civil han tenido por más de un siglo un valor nominal? ¿Deberían en consecuencia ser derogadas? Para concluir este análisis quiero aludir a una estrategia interesada en la acera explicativa del juicio de hecho, pero que rescata varias de las intuiciones de los enfoques mencionados: por una parte, el deseo de convencer a las personas de la racionalidad del relato acogido como el que mejor enhebra las pruebas recopiladas en relación a lo que ocurrió (enfoque interno) y, por otra, al uso de reglas (legales o no) que ayuden al juez a evaluar todas las piezas probatorias admitidas y a descifrar el peso o valor que merecen ellas en particular y cada narración en general (enfoque externo). De este enfoque intermedio pueden surgir razones para conservar algunas normas de prueba de nuestra ley procesal civil y pensar en otras que sirvan al trabajo judicial.

\section{LA INFERENCIA A LA MEJOR EXPLICACIÓN}

Los dos encuadres que he presentado pueden complementarse uno con otro. Esa posibilidad queda al descubierto gracias al modelo híbrido de la inferencia a la mejor explicación. Este modelo irrumpió en sede judicial proveniente desde la filosofía de la ciencia, especialmente de ciertos trabajos en inteligencia artificial, como un modo de razonamiento no formalizado. Bajo este esquema, mientras más elevado sea el apoyo entregado por las diversas pruebas a la conclusión del tribunal, menor el nivel de contradicción entre ellas y mayor su rango de plausibilidad, el juicio de los hechos será mejor ${ }^{64}$. Lo interesante de este razonamiento es que se prescinde de una explicación completa y única para el caso, pero se mantiene el foco en dos preguntas típicas del estándar de prueba: (i) la fuerza de los argumentos ofrecidos y (ii) la persuasión de los relatos. Ahora bien, dadas las exigencias judiciales este es un modelo que puede formalizarse de manera que apele tanto a razones

\footnotetext{
${ }^{60}$ FerRer (2007) pp. 139-152.

61 TARuffo (2003) pp. 668-669.

62 Wright (2009) pp. 87-91.

${ }^{63}$ Corte de Apelaciones de San Miguel, 15 de abril de 1992, Gaceta Jurídica, № 143, pp. 75-79.

${ }^{64}$ Cfr. Bex y Walton (2010) pp. 37 ss.
} 
derrotables (construidas paso a paso, desde las pruebas hacia los hechos), como a explicaciones sobre lo que pudo haber ocurrido (dos o más relatos acotados que compiten entre ellos). En justo en esta formalización del juicio de hecho donde los enfoques 'desde dentro' y 'desde fuera' del juicio de hecho se apoyan: la inferencia a la mejor explicación no solo echa mano a la forma en que los tribunales razonan en la práctica -explicando el caso-, sino que, además, acude a reglas de peso probatorio -otorgando a las pruebas una plausibilidad relativa según sean las historias contadas-.

La búsqueda de esta mejor explicación invita al tribunal a un ejercicio de razonamiento abductivo. El juez debe pensar las evidencias y los hechos de manera heurística para llegar a la causa desde los efectos. Para la filosofía de la ciencia el razonamiento abductivo es uno más de los candidatos a ser el método dominante de descubrimiento en el trabajo científico y no hay necesidad de pretender algo distinto tratándose de la tarea judicial. En cada caso el tribunal acude a una amplia baraja de razonamientos inferenciales cuando juzga. Siguiendo a Ilkka Niiniluoto podemos esquematizar estos recursos como sigue: el tribunal usa la deducción para conocer el resultado gracias a la regla aplicable y al caso: por ejemplo, "toda persona es mortal" (regla), "María es una persona" (caso), "María es mortal" (resultado deducido); la inducción, en tanto, le permite dar con la regla usando el caso y el resultado: "María es mortal" (resultado), "María es una persona" (caso), "toda persona es mortal" (regla inducida); y es la adbucción la que posibilita conocer el caso a partir de la regla y el resultado: "María es mortal" (resultado), "toda persona es mortal" (regla), "María es una persona" (caso abducido) ${ }^{65}$. Esta forma de conocimiento del caso fue lo que llamó la atención de la literatura sobre prueba. A partir de ella se pensó que el juez puede considerar las piezas probatorias diseminadas a lo largo del juicio para seleccionar la hipótesis que mejor retrata el conflicto, usando para este propósito un razonamiento ampliativo que no se limita a repetir esos medios de prueba (en el sentido trivial de enumerarlos), sino que desprendiendo de ellos el relato o historia que mejor explica el asunto debatido.

Por cierto que este ejercicio debe ser transparente en cuanto a los patrones de razonamiento que sigue el tribunal en la formación y evaluación de las hipótesis. El auditorio de los fallos debe poder identificar con sencillez cómo se generaron esas explicaciones -mediante una lógica de abducción en sentido débil (contexto de descubrimiento)-, y comprender las razones utilizadas para seleccionar la narración definitiva -por la vía de la abducción en un sentido fuerte o inferencia a la mejor explicación (contexto de justificación)-. Ambos aspectos integran el núcleo de la motivación de la sentencia ${ }^{66}$. Para lo que ahora nos interesa, la inferencia a la mejor explicación calza en la arquitectura del derecho de prueba tanto a un nivel micro como macro: (i) en un nivel micro ella sirve para anudar las diferentes evidencias entre sí, evaluando la relevancia de cada pieza probatoria e instando a que rija una regla de admisibilidad de todos los elementos pertinentes como norma general; (ii) en un nivel macro, en tanto, actúa sopesando los distintos relatos de la misma forma en que todos tomamos decisiones cotidianas, lo que hace del trabajo judicial un método que resulta familiar a los ciudadanos. La operatividad en ambos niveles permite al juez

\footnotetext{
${ }^{65}$ NiIniluoto (1999) p. 452.

${ }^{66}$ Amaya (2009) p. 136.
} 
navegar simultáneamente con una guía de las inferencias probatorias desde una perspectiva atomista y holista ${ }^{67}$. La inferencia a la mejor aplicación es, por ende, una agenda que aporta al juicio de hecho ese algo más que se necesita para justificar un fallo: cuando el juez dice que una evidencia "tiene valor probatorio", lo que anticipa es que hay buenas razones para sostenerlo 68 .

La plasticidad de los conflictos hace que en algunos casos podamos fijar ciertos fragmentos en el proceso civil con un alto nivel de consenso, pero, en otras muchas ocasiones, los hechos se fugan hacia la incertidumbre que envuelve toda discusión. Michael Pardo, uno de los autores que ha explorado la idea de la inferencia a la mejor explicación en el trabajo de los jueces, percibe que es posible conectar esta forma de razonamiento con normas que le entreguen al juez criterios para la aplicación de los estándares de prueba. Estas reglas de segundo orden son decisiones acerca de lo que deberían hacer los procesos judiciales para neutralizar los problemas asociados a una elección de primer orden -como juzgar los hechos-. Es decir, son preceptos que nos enseñan a interpretar un estándar de prueba en un cierto modo, distinguiendo sus aplicaciones legítimas de aquellas que no lo son ${ }^{69}$. Lo que me parece relevante de la propuesta de Pardo es que estas decisiones de segundo orden pueden construirse sobre criterios probabilísticos o explicativos al mismo tiempo, lo que acerca a los encuadres antes esbozados.

(1) Desde el punto de vista de las probabilidades el derecho de prueba puede asilarse en un valor cardinal explícito, como ocurre con el umbral 0,5 (probabilidad prevaleciente) o el de 0,75 (prueba clara y convincente). Ahora bien, como dije, dicho marcador es insuficiente porque reproduce las debilidades del estándar como regla de primer orden al abrir la puerta a las valoraciones de probabilidad que ha de hacer el tribunal. Incluso cuando el juez acierta con su valoración existe el peligro de que su estimación sea irracional (como creerle a un testigo porque tiene el pelo negro) o despreocupada de las pruebas disponibles, o bien, que no cuente con datos estadísticos suficientes para procesar esa información con parámetros objetivos. Lo grafico con el siguiente ejemplo: una norma de segundo orden de corte probabilístico es la que nos permite saber dónde hacer el corte cuando un litigante demanda en un juicio de responsabilidad que la publicación que lo difama ha sido maliciosa. Aquí la norma de primer orden, como se vio a propósito de Masson v. New Yorker Magazine, Inc., es un estándar de prueba clara y convincente. La norma de segundo orden, en tanto, es la disposición que le informa al juez que el rango a mirar a efectos de conocer si las publicaciones dolosas son o no frecuentes -o estadísticamente relevantes- es el de las publicaciones de los últimos cinco años, dentro de la región y que se refieran solo a personas que no desempeñan un cargo público. Esta sencilla regla de segundo orden cumple (en lugar de los pálpitos o intuiciones del juez) la tarea de discriminar las circunstancias que son relevantes para definir las probabilidades, cerrando el paso a la discrecionalidad judicial.

${ }^{67}$ Pardo y Allen (2008) pp. 223 ss.

${ }^{68}$ Pardo (2005) p. 375.

${ }^{69}$ Pardo (2009) pp. 1099-1104. 
(2) Desde la acera explicativa, en tanto, los relatos que se discuten pueden considerarse probados según lo bien que logran explicar las pruebas en relación a los hechos. El juez infiere sus conclusiones basado en cómo las proposiciones, de ser verdaderas, explican la prueba disponible de mejor modo que las otras historias en competencia. El primer desafío, entonces, consiste en identificar las narraciones que participan -en sede civil habitualmente cuentan las formuladas por las partes- y luego determinar la que ofrece una mejor explicación del conflicto en base a criterios de consistencia, simplicidad, coherencia con las creencias de trasfondo, consiliencia (la extensión en la cual tipos variados de hechos obtienen explicación) y la ausencia de premisas ad hoc. Lo que identifica a este tipo de normas de segundo orden es, en consecuencia, su sello dialógico.

Según el modelo diseñado por Pardo, si la regla de primer orden informa a los litigantes que en el proceso civil por regla general "un hecho debe acreditarse por la preponderancia de la evidencia", entonces la regla de segundo orden será que "un hecho está probado por la preponderancia de la evidencia cuando la mejor explicación de la prueba y del caso incluye ese hecho". La intuición de fondo es que entre las posibles explicaciones del caso la que mejor aclara los datos disponibles es probablemente la verdadera. Este enfoque consigue superar uno de los desafíos a la regla $\mathrm{P}>0,5$, la mantención del statu quo, dado que hace razonable fallar en casos donde el actor ha empujado su narración, por ejemplo, hasta un 0,4 de probabilidad, mientras que el demandado se mantiene en un 0,2. En un escenario así, la norma de segundo orden habilitaría al juez a aplicar el estándar de probabilidad prevaleciente en beneficio del demandante, minimizando los riesgos de errores (ya que acoge la tesis que más probabilidades tiene de ser verdadera) y derogando el privilegio que ese estándar le concede a los demandados (al no conservar el statu quo de un relato que tiene escasa plausibilidad). Pero, insisto, para que el juez civil pueda sacar estas conclusiones es fundamental que cuente con una norma de segundo orden que así lo establezca. La inferencia a la mejor explicación por sí sola no se encarga de repartir riesgos, "sino de atribuir grados de confirmación a las distintas hipótesis"70.

Lo que para Larry Laudan no son sino "extraños aliados" 71 , puede que para la justicia civil sea una posibilidad real de asegurar juicios justos y eficientes. Pero ciertamente que poner reglas de probabilidades y explicaciones a trabajar juntas para confeccionar un juicio de hecho correcto es una empresa no exenta de desafíos. Para concluir me limito a mencionar dos de ellos:

(1) La cuestión de las normas de tercer orden (y de $X$ orden) que pueden desbordar el derecho de prueba en su intento de hacer operativo el uso de modelos matemáticos o formales en el proceso civil. Si para evitar la discrecionalidad judicial apelamos a normas que ayudan a capturar las conexiones entre los datos y los hechos ocurridos, surge la necesidad de lidiar con el inconveniente fundamental de la prueba estadística: el problema de referirse a una clase en desmedro de otras. O sea, con la necesidad de justificar el "corte"

\footnotetext{
70 BAYÓN (2008) p. 16.

${ }^{71}$ Laudan (2007) p. 89.
} 
que los datos estadísticos hacen en la realidad. Por ejemplo, si un litigante cuestiona la credibilidad de un testigo en razón de una condena previa en un juicio de reivindicación, la objeción que puede formular su contraparte es inmediata: ¿por qué mirar solamente las condenas a testigos en este tipo de juicios patrimoniales y no el promedio de condenas en todo el universo de juicios civiles que involucren a la propiedad? O el escenario típico del peritaje: ¿por qué el actor podría cuestionar la confiabilidad del informe que escribe un restaurador sobre el estado de conservación de un antiguo edificio teniendo en cuenta las publicaciones de otros especialistas que publican en revistas internaciones? La respuesta para este tipo de objeciones son las normas de segundo (tercer, cuarto o $X$ ) orden. Esas reglas son el fundamento para el "corte" que hace la prueba estadística en el juicio, anulando el problema de la referencia a una clase ${ }^{72}$. El desafío estriba en dirimir cuántas de estas normas necesitamos.

(2) El "problema de la sub-consideración" o también conocido como el "argumento del lote malo"73. ¿Qué pasaría si todas las narraciones que compiten se encuentran erradas?, es decir, ¿cuáles son las probabilidades de que la (verdadera) explicación del caso integre el grupo de relatos que considera el juez? Para atenuar la inquietud de que la inferencia a la mejor explicación tendría un mal desempeño en tribunales porque sería "demasiado permisiva" 74 no basta con decir lo que típicamente esgrime el giro racionalista de la prueba, es decir, que se trata de un razonamiento derrotable ("porque toda nueva información puede hacer variar el fallo"), ya que ello reintroduciría el problema de la "aproximación contra-fáctica" ("todo depende de las decisiones probatorias que haya tomado el juez a cargo del caso"). Este desafío es muy interesante porque redirige el debate hacia el mínimo de responsabilidad que estamos dispuestos a exigir de cualquiera (y sobre todo del juez) que en un proceso esgrima una creencia como justificada. Ningún juicio acerca de los hechos opera en un "vacío conceptual", sino que depende y se ciñe a un conocimiento de trasfondo que vuelve plausible decir que la verdadera explicación de los hechos sí está entre las narraciones leídas por el tribunal.

La tarea de los jueces combina un razonamiento basado en la coherencia (para inferir la mejor explicación) con una responsabilidad epistémica (para dirimir que el conjunto de historias consideradas es suficiente $)^{75}$. (a) Lo primero les exige revisar las explicaciones que se han ofrecido para interpretar el conflicto con estrategias de adición, sustracción y reinterpretación (de elementos de prueba o de creencias) para calibrar su grado de coherencia. Se trata de un ejercicio de consolidación interno que luego cada tribunal debe complementar con uno de fusión externo que integre todo lo que se va añadiendo al juicio (sea una prueba o una creencia) con la información antigua; (b) lo segundo, en tanto, supone ciertos deberes epistémicos -no pedir reportes sobre hechos implausibles, por ejemplo- y algunas virtudes epistémicas -abrirse hacia todas las informaciones posibles, perseverar en una

\footnotetext{
72 Sobre esto véase Allen y Pardo (2007) pp. 107 ss.

73 Amaya (2009) pp. 152-155.

${ }^{74}$ Laudan (2007) p. 91.

${ }^{75}$ Amaya (2007) pp. 437-440.
} 
línea de exploración y una disposición para cambiar de enfoque si las pruebas lo sugieren-. La inferencia a la mejor explicación visibiliza estos deberes y virtudes en el diseño de los estándares de prueba. Un buen ejemplo al respecto es lo que Rodrigo Coloma llama estándar de la preferencia de las buenas explicaciones no derrotadas para los casos donde se juzga la violación de un derecho humano (un umbral que evita que una descripción consistente termine siendo derrotada por explicaciones mediocres) ${ }^{76}$.

En definitiva, es sensato pensar que el entendimiento del juez sobre el caso dependerá, en parte, de las creencias de quien juzga sobre lo verdadero o falso de los hechos, pero también de los costos y riesgos que entraña la adquisición de nuevos antecedentes. El aumento de estos riesgos y gastos debe balancearse con un incentivo epistémico irrenunciable para todo juez civil: conocer el caso. Así, sea cual sea la explicación del juez cuando motiva su veredicto es preciso que tenga conciencia del delicado balance entre esos dos objetivos antagónicos: recabar más datos con valor explicativo y evitar los riesgos de error ${ }^{77}$. Una de las reglas que mejor expone este compromiso de la justicia civil es el estándar de prueba. Dicho estándar suele ser presentado en el lenguaje de las probabilidades, pero lo cierto la lógica binaria de 'conocimiento/ignorancia' que grafica la escala 0 a 1 no basta para juzgar los hechos. Esperamos de un juez que justifique su 'grado de creencia' en que lo que resuelve es probablemente lo verdadero, aunque no sabemos bien en qué consiste ese 'grado de creencia $^{78}$. El estándar de prueba pretende ayudar en esta labor. Y aunque los errores seguirán cometiéndose incluso con un estándar claramente definido, ellos podrán ser identificados por la misma litigación (dado que "la práctica de usar la regla muestra también qué es un error en su utilización” $)^{79}$, lo que nos permitirá proyectar un reparto explícito de los mismos.

\section{RECUENTO}

Los jueces civiles fallan con información incompleta cada uno de los casos que llegan a su presencia. El estándar de prueba es una de esas normas que sirven para minimizar los riesgos de equivocarse en la medida que vela por un mínimo de razonabilidad en el juicio de hecho. Para aquellos escenarios en que la incertidumbre persiste, el estándar opera como un sistema de distribución no discrecional de dichos riesgos entre el actor y el demandado, vistos no como individuos sino como clases de litigantes. Entre las principales conclusiones que arroja el examen anterior me permito destacar las siguientes:

(1) En los procesos civiles patrimoniales parece adecuado trabajar con un estándar de probabilidad prevaleciente (regla $\mathrm{P}>0,5$ ) como precepto común y supletorio. Para identificar el estándar adecuado a cada juicio es preciso contar, primero, con un estudio empírico

\footnotetext{
${ }^{76}$ Coloma (2009) pp. 220-228 (destacado en el original).

77 PÁez (2006).

78 Eriksson y Hájex (2007) p. 185.

79 Wittgenstein (1969) p. 6c (29).
} 
LARroucau Torres, Jorge "Hacia un estándar de prueba civil"

que nos enseñe cómo han trabajado los jueces en esa área, para luego deliberar la mejor alternativa;

(2) Cuando los bienes en juego lo sugieran es posible aumentar el estándar exigido hacia uno de prueba clara y convincente (regla P>0,75), resguardando así la posición del demandado. Esto ocurre, por ejemplo, en los casos donde se acusa una actuación dolosa;

(3) Hoy la justicia civil chilena (en un sentido amplio: laboral, de familia y patrimonial) parece más enfocada en los beneficios que reporta invocar un estándar de prueba (en su caso: un estándar subjetivo de haberse convencido de la verdad de los hechos) y no en los costos que tiene juzgar un hecho, justificando el cómo reparte los riesgos de error;

(4) Esta actitud expone a la administración de justicia a dos peligros: (a) distribuir de forma (arbitraria por) discrecional el riesgo de error y (b) emplear en un conflicto civil un estándar similar al penal ("más allá de toda duda razonable"), lo que distorsiona el derecho de prueba;

(5) Desde un punto de vista analítico se pueden distinguir dos maneras de abordar el estándar de prueba: (i) un encuadre externo (amparado en reglas de peso probatorio) y (ii) un enfoque interno (basado en la convicción). Tanto la teoría como la práctica angloamericana han explorado en profundidad ambos caminos, por lo que es razonable prestarles atención, sobre todo cuando existe la inquietud de mejorar la adjudicación civil en Chile;

(6) La inferencia a la mejor explicación es una estrategia tomada desde la filosofía de las ciencias que rescata intuiciones del encuadre interno ('desde dentro') y externo ('desde fuera'), con el ánimo de equipar a nuestros jueces con lo necesario para juzgar los hechos correctamente. Junto con defender el razonamiento abductivo, esta perspectiva introduce la pregunta por las reglas de segundo orden y por los deberes y virtudes epistémicos del juez;

En una década donde se han visto las reformas más serias a nuestras formas de resolver los conflictos es intrigante observar que la pregunta por el resultado de la valoración de las pruebas no sea intensamente discutida. Espero que lo dicho en estos párrafos ayude a posicionarla como uno de los desafíos que debe sortear una justicia moderna, porque el proceso civil sigue siendo "un juego terriblemente serio" (Carnelutti dixit) y resulta bastante incómodo, por decir lo menos, participar en un juego con reglas poco claras.

\section{BIBLIOGRAFÍA}

Accatino, Daniela (2009): "Forma y sustancia en el razonamiento probatorio. El alcance del control sobre la valoración de la prueba a través del recurso de nulidad penal”, Revista de Derecho, vol. XXXII, Pontificia Universidad Católica de Valparaíso: pp. 347-362.

Allen, Ronald y pardo, Michael (2007): "The Problematic Value of Mathematical Models of Evidence", The Journal of Legal Studies, vol. 36 (1): pp. 107-140.

Anderson, Terence, Schum, David y Twining, William (2005): Analysis of Evidence, (Cambridge University Press, 2a Edición, Reimpresión, 2009) 401 pp.

Amaya, Amalia (2009): "Inference to the Best Legal Explanation", en: Kaptein, Hendrik, Prakken, Henry y Verheij, Bart (edit.), Legal Evidence and Proof: Statistics, Stories, Logic (Ashgate) pp. 135-160. 
Amaya, Amalia (2007): "Formal Models of Coherence and Legal Epistemology", Artificial Intelligence and Law, vol. 15: pp. 429 a 447.

Barzun, Charles (2008): "Rules of Weight", Notre Dame Law Review, vol. 83: pp. 19582018.

BaYón, Juan Carlos (2008): "Epistemología, moral y prueba de los hechos: Hacia un enfoque no benthamiano", ponencia presentada en el XIV Congreso Ítalo-Español de Teoría del Derecho, Girona (inédita): pp. 1-21.

Bentham, Jeremy (1825): Tratado de las pruebas judiciales, obra compilada de los manuscritos del autor por E. Dumont (Traducc. del francés por Manuel Ossorio Florit, Editorial Comares, Granada, 2001).

Bex, Floris y Walton, Douglas (2010): "Burdens and Standards of Proof for Inference to the Best Explanation”, Jurix, vol. 10: pp. 37-46.

Bierschbach, Richard y Stein, Alex (2007): "Deterrence, Retributivism, and the Law of Evidence”, Virginia Law Review, vol. 93: pp. 173-182.

Cerda, Rodrigo (2009): Valoración de la prueba. Sana crítica (Librotecnia, Santiago de Chile) $148 \mathrm{pp}$.

Choo, Andrew L-T (2009): Evidence (Oxford University Press, 2a Edición) 424 pp.

Clermont, Kevin y Sherwin, Emil (2002): “A Comparative View of Standards of Proof”, American Journal of Comparative Law, vol. 50: pp. 243-275.

Clermont, Kevin (2009): "Standards of Proof Revisited", Vermont Law Review, vol. 33: pp. 469-487.

Coloma, Rodrigo (2009): "Estándares de prueba y juicios por violaciones a los derechos humanos", Revista de Derecho, vol. XXII, No 2, Universidad Austral, Valdivia: pp. 205229.

Corral, Hernán (2003): Lecciones de responsabilidad extracontractual (Editorial Jurídica de Chile, Santiago) $423 \mathrm{pp}$.

DAMAšKa, Mirjan (1997): Evidence Law Adrift (Yale University Press, New Haven) 160 pp.

Díez, Raúl (1997): De la prueba del contrato. Estructura civil y procesal (Editorial Jurídica ConoSur, Santiago de Chile) 285 pp.

Dworkin, Ronald (1981): "Principle, Policy, Procedure", en: Dworkin, Ronald, A Matter of Principles (Harvard University Press, Cambridge, London, 1985) pp. 72-103.

Engel, Christoph (2009): "Preponderance of the Evidence versus Intime Conviction: A Behavioral Perspective on a Conflict between American and Continental European Law", Vermont Law Review, vol. 33: pp. 435-467.

Eriksson, Lina y Hájek, Alan (2007): “What are Degrees of Belief?”, Studia Logica, vol. 86: pp. 185-215.

Ferrer, Jordi (2010): "La prueba es libertad, pero no tanto. Una teoría de la prueba cuasibenthamiana”, en: ACCATINO, Daniela (coord.), Formación y valoración de la prueba en el proceso penal (AbeledoPerrot, LegalPublishing, Santiago de Chile) pp. 3-19.

(2007): La valoración racional de la prueba (Marcial Pons, Madrid-Barcelona-Buenos Aires) $166 \mathrm{pp}$. 
Larroucau Torres, Jorge "Hacia un estándar de prueba civil"

Fluet, Claude y Demougin, Dominique (2005): "Deterrence versus Judicial Error: A Comparative View of Standards of Proof", Journal of Institutional and Theoretical Economics, vol. 161 (2): pp. 193-211.

Fuentes, Claudio (2011a): "Consideraciones en torno a la idea del estándar de convicción en el proceso civil", en: Leturia, Francisco (edit.), Justicia civil y comercial: Una reforma ¿cercana? (Ediciones LyD, Santiago de Chile) pp. 173-205.

Fuentes, Claudio (2011b): "La persistencia de la prueba legal en la judicatura de familia", Revista de Derecho, Universidad Católica del Norte, 18, No 1: pp. 119-145.

Gascón, Marina (1999): Los hechos en el derecho. Bases argumentales de la prueba (Marcial Pons, Madrid-Barcelona, 2a Edición, 2004) 230 pp.

Hamer, David (2004): "Probabilistic Standards of Proof, Their Complements and the Error that Expected to Flow from There", University of New England Law Journal, vol. 1 (1): pp. 71-107.

Hamer, David (1994): "The Civil Standard of Proof Uncertainty: Probability, Belief and Justice”, The Sydney Law Review, vol. 16: pp. 506-536.

HaY, Bruce y SpIer, Kathryn (1997): "Burdens of Proof in Civil Litigation: An Economic Perspective", The Journal of Legal Studies, vol. 26 (2): pp. 413-431.

Ho, Hock Lai (2008): A Philosophy of Evidence Law. Justice in the Search for Truth (Oxford Monographs on Criminal Law, Oxford University Press) 347 pp.

Kaplow, Louis (1994): "The Value of Accuracy in Adjudication: An Economic Analysis", Journal of Legal Studies, vol. 23: pp. 307-401.

Kaye, David (2003): “Two Theories of the Civil Burden of Persuasion”, Law, Probabilities and Risk, vol. 2: pp. 9-13.

Kirchmann, Julius von (1847): La jurisprudencia no es ciencia (Traducc. de Antonio Tuyol Serra, Centro de Estudios Constitucionales, Madrid, 3a Edición, 1983).

Lando, Henrik (2002): "When is the Preponderance of the Evidence Standard Optimal", The Geneva Papers on Risk and Insurance, vol. 27 (4): pp. 602-608.

Larroucau, Jorge (2011): "Res ipsa loquitur: Quien habla es el juez, no la cosa”, en: Figueroa, Gonzalo, Barros, Enrique y Tapia, Mauricio (coord.), Estudios de Derecho Civil VI (LegalPublishing, Santiago de Chile) pp. 491-519.

(2007): Culpa y dolo en la responsabilidad extracontractual. Análisis jurisprudencial (LegalPublishing, Santiago de Chile) 233 pp.

LAUDAN, Larry (2007): "Aliados extraños: La inferencia a la mejor explicación y el estándar de prueba penal”, en: Laudan, Larry, El estándar de prueba y las garantías en el proceso penal (Traducc. Edgar Aguilera, Hammurabi, Buenos Aires, 2011) pp. 89-115.

Laudan, Larry (2006): Truth, Error and Criminal Law. An Essay in Legal Epistemology (Cambridge Studies in Philosophy and Law, Cambridge University Press) 233 pp.

Macbride, Ennis (2009): “Is the Civil 'Higher Standard of Proof' a Coherent Concept?", Law, Probabilities and Risk, vol. 8: pp. 323-351.

Nieva, Jordi (2010): La valoración de la prueba (Marcial Pons, Madrid-Barcelona-Buenos Aires) $374 \mathrm{pp}$.

Niıniluoto, Ilkka (1999): "Defending Abduction”, Philosophy of Science, vol. 66 (3): pp. 451-467. 
Ormazabal, Guillermo (2004): Carga de la prueba y sociedad del riesgo (Marcial Pons, Madrid-Barcelona) $135 \mathrm{pp}$.

PÁez, Andrés (2006): “The Epistemic Value of Explanation”, en: VVAA, Philosophy of Science Assoc. 20 $0^{\text {th }}$ Biennial Mtg (Vancouver).

Pardo, Michael y Allen, Ronald (2008): "Juridical Proof and the Best Explanation", Law and Philosophy, vol. 27 (3): pp. 223-268.

Pardo, Michael (2009): "Second-Order Proof Rules", Florida Law Review, vol. 61: pp. 1083-1113.

Pardo, Michael (2005): "The Field of Evidence and the Field of Knowledge", Law and Philosophy, vol. 24: pp. 321-392.

Porat, Ariel y Stein, Alex (2001): Tort Liability under Uncertainty (Oxford University Press) $214 \mathrm{pp}$.

Redmayne, Mike (1999): "Standards of Proof in Civil Litigation", Modern Law Review, vol. 62: pp. 167-195.

Rioseco, Emilio (1995): La prueba ante la jurisprudencia. Derecho civil y procesal civil (Editorial Jurídica de Chile, Santiago, 3a Edición) t. I 491 pp, t. II 463 pp.

Sanchirico, Chris (1997): "The Burden of Proof in Civil Litigation: A Simple Model of Mechanism Design”, International Review of Law \& Economics, vol. 17 (3): pp. 431 447.

Schauer, Frederick (2003): Profiles, Probabilities and Stereotypes (The Belknap Press Harvard University Press, Cambridge, London) 359 pp.

Stein, Alex (2008): "Constitutional Evidence Law", Vanderbilt Law Review, vol. 61: pp. 65-124.

Stein, Alex (2005): Foundations of Evidence Law (Oxford University Press, Reimpresión 2008) $248 \mathrm{pp}$.

Stein, Alex (1998): "An Essay on Uncertainty and Fact-Finding in Civil Litigation, with Special Reference to Contract Cases", University of Toronto Law Journal, vol. 48: pp. 299-351.

Stein, Alex (1997): "Against 'Free Proof”, Israel Law Review, vol. 31: pp. 573-589.

(STEIN, Alex 1996): “The Refoundation of Evidence Law”, Canadian Journal of Law \& Jurisprudence, vol. 9: pp. 279-342.

Stein, Alex (1991): "Criminal Defences and the Burden of Proof", Coexistence, vol. 28: pp. 133-147.

TARuffo, Michele (2009): Simplemente la verdad. El juez y la construcción de los hechos (Traducc. de Daniela ACCATINO, Marcial Pons, Madrid-Barcelona-Buenos Aires, 2010) $299 \mathrm{pp}$.

Taruffo, Michele (2003): "Rethinking the Standards of Proof", American Journal of Comparative Law, $\mathrm{N}^{\circ}$ 51: pp. 659-676.

TARuffo, Michele (1992): La prueba de los hechos (Traducc. de Jordi FERRER, Trotta, Madrid, 2002) $542 \mathrm{pp}$.

TaVolari, Raúl (1999): "Variaciones sobre la prueba en el proceso (Viejos y nuevos temas probatorios)”, Revista de Derecho y Jurisprudencia, t. XCV: pp. 37-59. 
Twining, William (2006): Rethinking Evidence. Exploratory Essays (Cambridge University Press, 2a Edición) $511 \mathrm{pp}$.

Ugarte, José Luis (2009): "Tutela laboral de derechos fundamentales y carga de la prueba”, Revista de Derecho, vol. XXXIII, Pontificia Universidad Católica de Valparaíso: pp. 215-228.

VARs, Fredrick (2010): “Toward a General Theory of Standards of Proof”, Catholic University Law Review, vol. 60 (1): pp 1-47.

Weinstein, Jack (1966): "Some Difficulties in Devising Rules for Determining Truth in Judicial Trials”, Columbia Law Review, vol. 66, No 2: pp. 223-246.

Wittgenstein, Ludwig (1969): Sobre la certeza (Traducc. de Josep Lluís Prades y Vicent RaGA, Gedisa, Barcelona, 2006) 97 pp.

Wright, Richard (2009): "Proving Facts: Belief versus Probability", en KozIol, Helmut y Steininger, Bárbara (edit.), European Tort Law, pp. 79-105.

Zuckerman, Adrian (1994): "Quality and Economy in Civil Procedure. The Case for Commuting Correct Judgments for Timely Judgments", Oxford Journal of Legal Studies, vol. 14, No 3: pp. 353-387. 